\title{
PRODUÇÃO TEXTUAL DO GÊNERO WEBAULA NO FORMATO E-BOOK: DESCRIÇÃO DO PROCESSO DE ESCRITA
}

\author{
Débora Liberato Arruda Hissa ${ }^{1,2}$, Nukácia Meyre Silva Araújo ${ }^{2}$ \\ ${ }^{1}$ Instituto Federal de Educação, Ciência e Tecnologia do Ceará (IFCE) \\ Diretoria de Educação a Distância \\ ${ }^{2}$ Universidade Estadual do Ceará (UECE) \\ <debarruda@gmail.com>, <nukacia@gmail.com>
}

DOI: $10.21439 /$ conexoes.v10i2.711

\begin{abstract}
Resumo. Neste trabalho, descreveremos o processo de escrita do gênero webaula no formato de $e$ book. Apresentaremos as etapas do planejamento da produção textual do e-book, as adequações feitas na linguagem para a EaD e inserções de recursos, como links, avatar, áudio e vídeo. Analisaremos a distribuição das diferentes funções e tarefas entre os sujeitos produtores do texto, a fim de discutirmos as implicações desse processo de produção coletiva de um texto que se materializará em um gênero hipertextual.
\end{abstract}

Palavras-chaves: Processo de escrita. Webaula. E-book interativo.

\begin{abstract}
In this paper, we describe the writing process of the genre webclass in e-book format. We will present the steps of e-book text production planning, the adjustments made in the language for DL and the insertion resources such as links, avatar, audio and video. It will be analyzed the distribution of different functions and tasks between the text producer subjects in order to discuss the implications of this process of the aggregates production of a text that will be materialized in a hypertextual genre.
\end{abstract}

Keywords: Writing process. Webaula. Interactive e-book.

\section{INTRODUÇÃO}

O desenvolvimento de ambientes virtuais de aprendizagem implica o processo de escrita do material educacional digital (MED) concretizado nas webaulas, isto é, implica a fase em que se produzem os conteúdos informacionais e as relações entre eles; a sequenciação didática e a forma de apresentação multimodal em um ambiente virtual próprio para a Educação a Distância. Neste processo de escrita, interferirão tanto os aspectos específicos de escrita científica e acadêmica, por se tratar de webaulas destinadas a alunos de curso de ensino superior, como aspectos didáticos que priorizarão a interação e o diálogo entre os sujeitos envolvidos.

A webaula deverá refletir a proposta didática previamente definida pelos cursos de Educação a Distância, por isso deve estar em total sintonia com o enfoque didático que se pretende dar ao projeto educativo da instituição de ensino que trabalha com Material Educacional Digital (MED). Neste sentido, o processo de produção da escrita hipertextual - o qual terá sua materialização na forma de conteúdo verbalizado, imagens, vídeos, áu- dio, links e ícones - tem um papel fundamental para a realização do processo de ensino-aprendizagem em EaD. Logo a produção hipertextual dos textos-base da webaula, das tarefas e atividades propostas associadas a ela, dos recursos multimodais interativos utilizados, da linguagem dialogal deve ser pensada de forma a auxiliar na leitura/compreensão de texto para fins pedagógicos. Do contrário, corre-se o risco de termos uma webaula cheia de recursos multimodais e hipertextuais que em nada facilitam a aprendizagem, especialmente se considerarmos que o leitor/aluno pode trazer outras expectativas/experiências de leitura (já que a leitura para estudo é diferente da leitura por prazer). Por isso, ao produzirmos MED em formato webaula, muitas vezes, na elaboração do conteúdo, não podemos nos esquecemos de pensar no outro, no caso no aluno, como sujeito principal do processo de escrita em EaD.

Este artigo tem como propósito descrever, a partir de aspectos composicionais, que dizem respeito à estrutura do texto, seu conteúdo temático e seu estilo (BAKHTIN, 2003), o processo de escrita do gênero webaula 
no formato de $e$-book desenvolvido pela Diretoria de Educação a Distância do Instituto Federal de Educação, Ciência e Tecnologia do Ceará (IFCE). Apresentaremos as etapas do planejamento da produção textual, desde a concepção do texto no formato impresso até a versão multimodal apresentada na interface de $e$-book interativo e analisaremos como ocorre a negociação de sentidos entre os sujeitos envolvidos no processo de escrita multimodal em uma plataforma hipertextual.

\section{Webaula: considerações iniciais sobre a produção textual}

Antes descrevermos o processo de produção escrita de uma webaula no formato $e$-book interativo idealizado pelo Instituto Federal de Educação do Ceará (IFCE), discutiremos pontos que julgamos relevantes no que diz respeito a escrita de uma webaula. Trata-se de um gênero discursivo de escrita colaborativa próprio de ambientes virtuais de aprendizagem cuja produção escrita envolve vários atores e apresenta características típicas dos textos constituídos nesse espaço de interação (ARAÚJO, HISSA, ZAVAM, no prelo). Este gênero reúne características do gênero oral aula, de gêneros escritos de cunho didático (a própria escrita didática) e de gêneros que circulam no domínio hipertextual (aspectos multimodais e hipertextuais). A aula virtual está inserida em um ambiente virtual de aprendizagem (AVA), onde interagem estudantes e professores por meio do material escrito na forma de webaula, constituindo-se este um novo cenário para a comunicação didática, para a aquisição de conhecimento e para o desenvolvimento de habilidades e atitudes pelos sujeitos envolvidos neste contexto de ensino-aprendizagem.

Para Batista (2006), um ambiente virtual de aprendizagem constitui um espaço propício para que os estudantes obtenham meios didáticos e recursos interativos para interagir e realizar atividades cujas metas e propósitos educativos foram previamente estabelecidos ainda na fase inicial de pré-produção escrita da webaula. Ainda segundo Batista, existem quatro elementos essenciais em um AVA: 1. Um processo de interação ou comunicação entre sujeitos; 2 . Um grupo de ferramentas ou meios de interação; 3. Uma série de ações reguladas relativas a certos conteúdos; e 4. Um entorno ou espaço onde se materializam estas atividades. Uma interessante contribuição desse autor foi distinguir dois tipos de elementos no AVA: os constitutivos (que se referem aos meios de interação, recursos, fatores ambientais e psicológicos) e os conceituais (que se referem aos aspectos que definem o conceito educativo de AVA: o design instrucional e a interface).

No tocante aos meios constitutivos, no que diz res- peito aos meios de interação, Batista (op. cit.) ressalta que, enquanto em uma aula presencial a interação é predominantemente oral,em uma webaula a interação se dá de modo predominantemente escrito. Neste modo de interação, a escrita pode ser multidirecional, isto é, pode se ter um intercâmbio de ideias que se realiza de forma sequenciada, síncrona ou assíncrona, com perguntas e respostas, convertendo-se em um processo circular de ida e volta. Como exemplo desse modelo de interação escrito multidirecional que acontece na webaula, tem-se o e-mail, os links para vídeos, os fóruns de discussão, etc. nos quais a informação flui em dois ou mais sentidos, como um diálogo (BATISTA, 2006).

Esta descrição do modelo de escrita multidirecional conjuga-se com a definição de webaula como um gênero híbrido feita por Araújo, Hissa, Zavam (no prelo). No caso da webaula, tem-se um gênero híbrido, composto de textos multimodais (o próprio texto escrito principal que, por meio de links ou de inserções no próprio corpo do texto, apresenta também, por exemplo, imagens estáticas ou em movimento, sons, etc.) e de outros gêneros típicos da modalidade $\mathrm{EaD}$, tais como fóruns, listas de discussão, wikis, chats educacionais, entre outros (ARAÚJO, HISSA, ZAVAM, no prelo).

Com relação aos elementos conceituais do AVA, Batista (idem) também os divide em dois: design instrucional, como a forma que se planeja a webaula desde os objetivos, a produção das atividades, as estratégias e técnicas didáticas, a avaliação até a retroalimentação (feedback); e a interface, ou seja, a expressão visual e formal da webaula. Ressalta este autor que existem vários fatores que influenciam o design instrucional e a interface em um AVA. Logo, a produção escrita de uma webaula dependerá da natureza do curso, das características dos estudantes, das possibilidades de recursos interativos da equipe de produção, do suporte computacional, etc.

Hueros e Franco (2011) também tratam da produção escrita de uma webaula como dependente de vários fatores. Segundo eles, o processo de produção ocorre em três fases: $1^{\mathrm{a}}$ fase inicial (no IFCE chamamos de fase de produção da matriz do Design Instrucional) na qual se planejam os objetivos da webaula; $2^{\mathrm{a}}$ fase de design e documentação (no IFCE, fase de escrita verbal e multimodal da webaula) e $3^{\mathrm{a}}$ fase de realização e de postagem da webaula no AVA que terminará com uma análise do seu funcionamento e operacionalidade. Hueros e Franco ressaltam que uma webaula deve aproveitar ao máximo a tecnologia hipermídia e as ferramentas de comunicação disponíveis no AVA, a fim de otimizar o processo de ensino-aprendizagem. Para ele, a produção de uma webaula requer uma análise de todas as 
variáveis didáticas que intervêm nesse processo.

Hueros e Franco (2011, p. 178), assim como Batista (2006), também levantam questões que eles julgam basilares para a produção da webaula. Pontos como quem são os destinatários; de que natureza são os conteúdos produzidos; quais as competências tecnológicas dos usuários; que nível de motivação os usuários apresentam diante de uma webaula fazem parte do rol de reflexões que devem ser levadas em consideração no processo de escrita.

Ainda no que se refere à produção de uma webaula, Almerara (2011, p. 219) descreve dois diferentes princípios para se considerar a produção de materiais didáticos para a EaD: pedagógico-narrativo (que se refere à escrita do conteúdo) e estético-técnicos (que se refere à inserção dos elementos multimodais). Para este autor, a produção de uma boa webaula dependerá mais dos princípios pedagógico-narrativos que, por sua vez, dependerão da concepção contextual e científica que se tem em conta na hora da produção da webaula. Almenara salienta que a produção de materiais para o AVA é totalmente diferente da criação de textos planos, isto é, de textos criados para o meio impresso. Para ele, a webaula deve incluir diferentes elementos que vão desde a exposição dos objetivos que o professor pretende que o aluno alcance, o esquema dos conteúdos a desenvolver na webaula, a existência de uma introdução e apresentação de recomendações para o estudo, a proposta de atividades que os alunos devem realizar, a existência de elementos de aprofundamento e extensão dos conteúdos oferecidos, sumário das ideias mais significativas desenvolvidas na webaula e resumo dos aspectos mais importantes tratados.

Rodríguez da las Heras (2002) reflete que, aos espaços seculares para a transmissão do conhecimento, como o arquitetônico da sala de aula e da leitura da página, se une um novo: o da tela do computador, e um erro que se comete é tentar reproduzir neste novo espaço aquilo que já está bem estabelecido nos outros. Las Heras afirma que é preciso seguir duas novas regras que dizem respeito à incorporação do texto para o novo espaço de interação: $1^{\circ}$ ) não transferir para a tela atividades que se realizem em outros meios sem aplicar mudanças severas que as reajustem para o novo suporte; e $2^{\circ}$ ) explorar o que ele traz de novidade, de recursos, de ferramentas e descobrir aquilo que os outros suportes de texto não podem oferecer.

Atualmente, cada instituição de ensino superior que trabalha com EaD tem seu próprio modelo de produção do material educacional digital, que muitas vezes muda de acordo com as situações de interação. Na maioria das vezes, nestes locais, são utilizadas quatro possibili- dades de planejamento para a criação das aulas no AVA: 1) utilizam-se materiais que não foram criados especificamente para a EaD e estes são transferidos como qual estão feitos no modelo impresso para o Ambiente Virtual de Aprendizagem; 2) adaptam-se para o AVA materiais didáticos que não foram criados especificamente para $\mathrm{EaD}$; 3 ) utilizam-se nas webaulas materiais que foram criados sim para $\mathrm{EaD}$, porém que foram produzidos em outras instituições de ensino que não aquela em que estão sendo usados; e 4) elabora-se o próprio material didático pela instituição em que será utilizado, o que acontece no IFCE, nosso contexto de análise. Veremos no próximo tópico como são as etapas do processo de escrita de uma webaula no IFCE, seus sujeitos-autores e as formas de negociação de sentido para a escrita colaborativa desse gênero discursivo.

\section{Webaula: produção escrita colaborativa}

Produzir uma webaula significa escrever com os vários sujeitos-autores que estão diretamente ligados ao processo de escrita do material. Aretio (2011, p.192) explica que, na produção dos materiais para a EaD, tem-se um continuum, no qual, em um extremo, situase o professor-autor (aquele que trabalha individualmente e que não tem os conhecimentos precisos sobre a metodologia em EaD); enquanto, no outro extremo do continuum, encontra-se a equipe multidisciplinar (com especialistas de diferentes âmbitos que irão confluir na elaboração de webaula). Aretio explica que, se o professor-autor escrever sozinho o material didático que será postado na forma de uma webaula - ou seja, escrever sem a colaboração da escrita da equipe multidisciplinar, serão desconsideradas as peculiaridades dos recursos de uma escrita multimodal própria de EaD. Para Aretio, este escrito, embora pudesse ter um formato tanto impresso quanto eletrônico, poderia até ser bom, do ponto de vista do conteúdo, porém serviria mais como um apoio para o ensino presencial do que como uma webaula.

Para explicar o processo de escrita colaborativa em EaD, Aretio (2011, p. 110) destaca que, enquanto no ensino presencial o professor organiza, produz, distribui, desenvolve e avalia ao longo de todo o processo de ensino-aprendizagem; em $\mathrm{EaD}$, o professor nunca é um, uma vez que são diversos os agentes que intervêm no processo de ensinar e aprender, até o ponto que chegamos a reconhecer a instituição, mais do que o professor, como responsável por ensinar, ou seja, é a instituição (os sujeitos-autores) que organiza, produz, desenvolve todo o processo de aprendizagem dos estudantes.

$\mathrm{Em} \mathrm{EaD,} \mathrm{este} \mathrm{processo} \mathrm{de} \mathrm{ensino-aprendizagem} \mathrm{se}$ dá pela escrita, melhor dizendo, se dá pela interação que 
o aluno faz com o material educacional digital. Para Asinsten (2007, p. 40) a linguagem escrita é a principal ferramenta de comunicação de conteúdos em EaD. O autor é enfático em dizer que, "falem o que falem, o peso principal do material didático em EaD recai sobre os documentos textuais escritos" (idem, p.57). Porém não basta que estes documentos escritos expressem a "verdade científica", pois como na Educação a Distância o professor não está presente de forma síncrona para "esclarecer conceitos, propor exemplos ou metáforas; o texto necessita ser compreensível por ele mesmo" (ASINSTEN, 2007, p 13).

Logo os sujeitos-autores devem adquirir novas habilidades para conseguirem êxito nessa produção colaborativa de uma webaula, habilidades estas que Asisten (idem, p.18) chamou de novas competências. Ele dividiu estas competências em três grandes grupos: as competências pedagógicas, as competências comunicativas e as competências tecnológicas. A escrita de uma webaula faria então parte da competência comunicativa. Daremos ênfase neste estudo à descrição dessa competência.

Asisten também dividiu a competência comunicativa em três grupos: 1. Competência na produção de texto, 2. Competência em comunicação com recursos multimodais e 3 . Competência em comunicação utilizando as novas tecnologias (Figura 1).

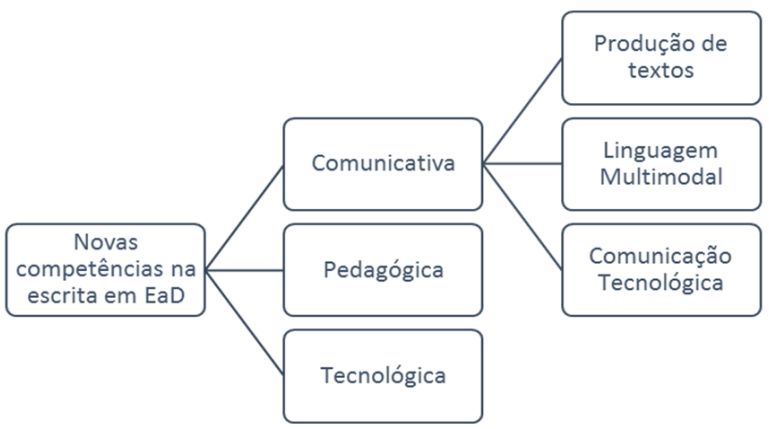

Figura 1: Resumo das Competências Docentes em EaD estabelecidas por Asinsten (2007).

No que se refere à competência na produção de textos, Asinsten (idem, p 22) a caracteriza como a capacidade para a) produzir textos dialógicos, abertos à reflexão, à dúvida, ao pensamento crítico; b) produzir textos amenos, fluídos, que envolvam o autor e o leitor; c) produzir períodos claros, taxativos e sintéticos; d) estruturar e organizar adequadamente a informação; e) utilizar os recursos visuais disponíveis (tipografia, formatos de parágrafo, quadros, barras, etc.); f) produzir textos adequados ao gênero. Já sobre a competência comuni- cativa com recursos multimodais, o autor explica que se trata da interpretação e produção de mensagens utilizando recursos não verbais nem escritos. Como exemplo dessa competência, aponta as capacidades de selecionar imagens adequadas para os propósitos do texto; de produzir ou manipular imagens; de integrar mensagens de diversos sistemas de códigos em linguagem multimodal; de adequar mensagens audiovisuais às características de diversos suportes, etc. Finalmente a competência em comunicação utilizando as novas tecnologias seria aquela que o sujeito-autor faz quando se mostra letrado digitalmente ${ }^{1}$, melhor ainda, quando utiliza os gêneros que pertencem ao contexto de uma webaula de forma eficiente. Segundo Aisnsten (p.23) essa eficiência se mostra quando o sujeito-autor do processo de escrita aprende a interpretar consultas dos alunos (por e-mail), quando responde aos alunos ajudando a encontrar as respostas sem dá-las (salvo em situações excepcionais), quando participa e intervém nos fóruns de discussão ou chats.

O que podemos observar de contínuo na análise dos autores que estudam sobre o processo de escrita de MED em EaD (mais especificamente a escrita da webaula) é que todos descrevem o processo mediante fase distintas em que se confluem sujeitos que possuem diferentes letramentos digitais. Batista (2001) deixa claro que o processo de escrita em ambientes virtuais de aprendizagem é uma tarefa particularmente interdisciplinar na qual é necessária a participação de especialistas em três âmbitos diferentes do conhecimento: $1^{\circ}$. Especialistas no tema da webaula, para definir e hierarquizar os conteúdos; $2^{\circ}$. Especialista em educação, para estudar e estabelecer as estratégias de escrita adequadas para a aprendizagem; e $3^{\circ}$. Especialistas em designer de interface, para propor o melhor uso dos recursos disponíveis no AVA, a fim de garantir uma navegação adequada e uma boa apresentação da informação.

Esta confluência de sujeitos-autores é a base do processo de escrita em EaD, uma vez que se está desenvolvendo uma atividade social cuja colaboração, o diálogo e a interação configuram-se ações interdependentes para que se tenha unidade na construção textual. Neste artigo, queremos levantar justamente uma discussão sobre como este processo de escrita colaborativa ocorre e quais as implicações que esta relação comunicativa interpessoal entre os sujeitos-autores pode influenciar o contexto de ensino-aprendizagem do aluno. Assim, levaremos para o próximo tópico desse estudo as seguintes questões: como a negociação de sentidos no processo de escrita colaborativa se dá entre os sujeitos envolvidos na produção de uma webaula? Como

\footnotetext{
${ }^{1}$ Tomamos esta competência como Letramento digital em EaD
} 
e com qual finalidade acontece a inclusão dos recursos multimodais e hipertextuais? Que adequações na linguagem são feitas em busca de uma maior interatividade na produção de uma webaula? A fim de explorar estas questões, descreveremos as etapas de produção escrita de uma webaula. Veremos que há um complexo plano de escrita colaborativa idealizado por diferentes sujeitos cuja intenção é desenvolver um produto que seja o mediador do processo de ensino-aprendizagem em EaD.

\section{Webaula: etapas de produção escrita}

Nesta seção, descrevemos uma webaula (aula 1) de Português Instrumental produzida pelo Instituto Federal de Educação, Ciência e Tecnologia do Ceará (IFCE), no âmbito do curso de Licenciatura em Educação Profissional, Científica e Tecnológica, que tem como interface no AVA o e-book interativo. A webaula foi desenvolvida a partir de um trabalho conjunto feito pela equipe multidisciplinar da Diretoria de Educação a Distância do IFCE (<http://dead.ifce.edu.br $>$ ), formada por professores especialistas no conteúdo das disciplinas, designers instrucionais, revisores, ilustradores e diagramadores.

A produção da webaula tem como objetivo principal a criação de um texto que não só apresente adequadamente o conteúdo de ensino, mas também motive os alunos, sane as possíveis dúvidas, mantenha um diálogo permanente com aqueles que participam do processo de ensino-aprendizagem, oriente-os e permita avaliação da aprendizagem, entre outros aspectos relevantes em uma aula.

Vimos que um dos aspectos que podem contribuir para a estrutura adequada do texto didático concretizado no gênero webaula é o planejamento da escrita. Ele deve passar pelos aspectos composicionais do texto, que dizem respeito a sua estrutura; pelo conteúdo temático, que se refere ao estabelecimento de propósito comunicativo, e pelo estilo e adequação do texto considerando-se o propósito e a audiência (os leitores) a quem se destina.

No caso do IFCE, a estrutura base de cada webaula contém introdução, objetivos, tópicos de aula - com os resumos e fechamentos de cada seção - referências e atividades. No texto principal, encontram-se facilitadores discursivos (quadros, tabelas, gráficos, esquemas organizacionais), recursos interativos (ícones e links recomendados).

Com relação ao estilo, a linguagem deve apresentar um tom dialogal mantendo-se o grau de formalidade exigido em um texto didático, porém conservando a pessoalidade na forma de se dirigir ao interlocutor. Nas orientações de produção de material didático do IFCE, essas premissas são fundamentais para se iniciar a produção escrita de uma webaula.

Essa produção propriamente dita da webaula surge a partir dos pressupostos estabelecidos na Matriz do Design Instrucional (Matriz DI). Nesta matriz, estabelecese a metodologia de produção escrita (como se organizará o processo de escrita colaborativa?), os sujeitosatores envolvidos (quem escreverá a webaula?), os objetivos (para quê se produz este material? Quais propósitos educativos/formativos/instrutivos deve cumprir?) e os conteúdos da webaula (que aspectos curriculares a webaula deve cumprir?). Nela também se definem os destinatários (como são e o que sabem os alunos que terão acesso à webaula?), estima-se a carga-horária (qual tempo é disponibilizado para que os alunos atinjam os objetivos previstos?), enfim, pensa-se globalmente a webaula. Esta matriz também é feita colaborativamente.

Depois ela é encaminhada para o professor-autor (chamado no IFCE de professor-conteudista, aquele que é especialista no assunto da webaula). Em média, um professor-conteudista escreve quatro aulas. Cada aula deve ter entre 12 a 15 páginas (dependendo da disciplina e do conteúdo), com 3 a 4 divisões temáticas (tópicos de aula). O professor-conteudista tem que conhecer o gênero webaula para que possa escrever a um aluno de EaD. Ora, como já dissemos, em EaD, quase toda a comunicação está mediada por textos, logo atender e respeitar as nuances tanto do gênero webaula como outros que existem dentro dela na hora de escrever é fundamental para ajudar os alunos-leitores a construírem esquemas de interpretação, esquemas estes elaborados socialmente por meio das expectativas construídas previamente diante de um gênero no AVA, como é o caso da webaula. A primeira versão da webaula, escrita pelo conteudista, terá a seguinte estruturaçãopadrã $2^{2}$ nos cursos de EaD no IFCE (Figura 2).

Esta versão, quando pronta, será encaminhada para o Designer ${ }^{3}$ Instrucional (aquele que é especialista em $\mathrm{EaD}$. Geralmente de formação acadêmica bastante variada). Ele fará a adaptação de todo o material escrito no formato impresso para o formato digital. Essas adaptações são negociadas diretamente com o conteudista, em idas e vindas de produção. Tem-se aí o primeiro nível de interação que resultará no primeiro escrito colaborativo.

Na Figura 3 é apresentado como este processo de

\footnotetext{
${ }^{2}$ Como já dissemos, esta estrutura pode variar tanto na quantidade de tópicos quanto na quantidade de tema.

${ }^{3}$ Muitos autores já começam a se referir a este sujeito-autor como Designer Educacional.
} 


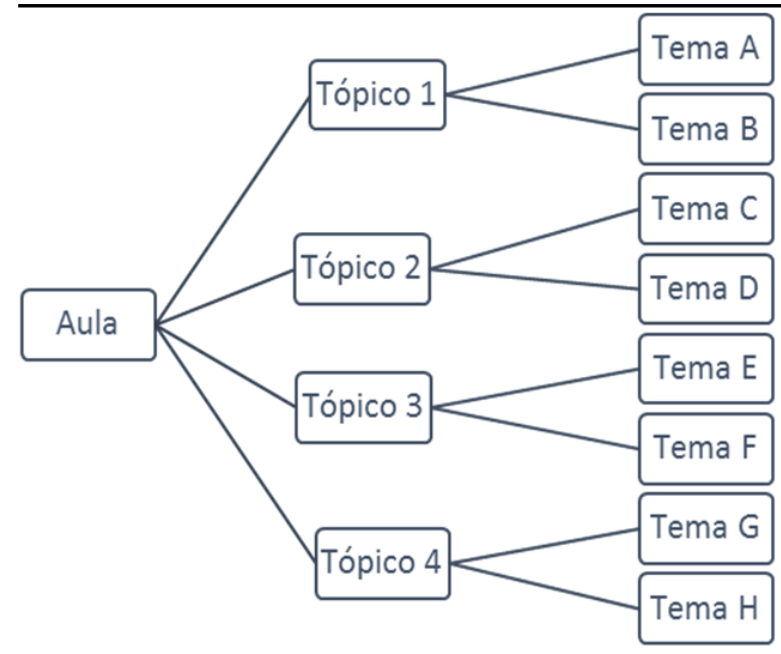

Figura 2: Estrutura Hierárquica de uma webaula: primeira versão produzida pelo conteudista.

negociação de sentidos na escrita ocorre. Podemos observar, nas barras de comentários à direita, dois sujeitos-autores "escrevendo" a webaula de forma colaborativa.

\section{Processo de escrita coletiva}

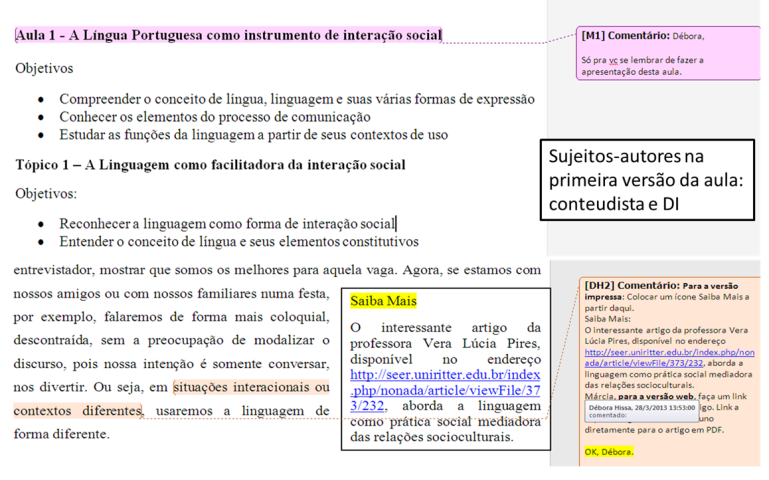

Figura 3: Negociação de sentido entre o conteudista e o DI.

Pode-se observar na referida figura que o professor conteudista, a partir da Matriz DI da disciplina de Português Instrumental, escolheu um título (A Língua Portuguesa como instrumento de interação social); determinou três objetivos gerais que os estudantes devem atingir ao final da leitura da aula 1; elaborou um tópico de abertura (A Linguagem como facilitadora da interação social); iniciou a apresentação do conteúdo, sugeriu a inserção de um ícone Saiba Mais, etc. Enquanto isso, o DI propõe acréscimos/redução de conteúdo, palavraschave que deveriam ser relacionadas ao ícone; links e imagens que devem aparecer em um gênero com características multimodais. Tudo isso por meio de um "diálogo" feito com o conteudista.

Depois esta nova versão segue para um novo sujeitoautor, o revisor textual (terceiro nível de interação), conforme Figura 4 Ele colaborará na escrita da webaula tanto na revisão ortográfica ou textual, quanto no acréscimo ou na modificação no que se refere a aspectos de apresentação do conteúdo. Este sujeito também "dialoga" com os outros sujeitos do primeiro nível de interação. Com a escrita do revisor, tem-se a terceira versão da webaula. Esta versão é novamente encaminhada para o DI (ou volta para o conteudista se houver muitas modificações de conteúdo) para que sejam feitas as alterações e que a webaula atinja a quarta versão. Nela dois outros sujeitos-autores entram no processo de escrita: o diagramador (especialista na interface em EaD) e o ilustrador (especialista em imagens).
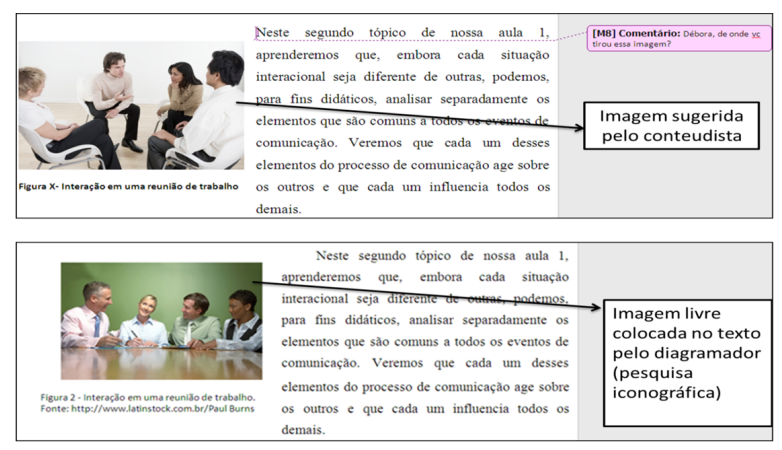

Figura 4: Modificação na imagem da webaula feita pelo ilustrador.

Na Figura 5 encontra-se um exemplo de negociação de sentido onde podemos distinguir todos os sujeitosautores envolvidos no processo de escrita da webaula.

Em seguida, depois de todo processo de escrita da webaula, esta será inserida no Ambiente virtual de aprendizagem com a interface de um e-book interativo, conforme Figura 6

Como se vê pela descrição do processo de escrita, a webaula reúne sujeitos-autores que estão diretamente envolvidos com a produção desse gênero. Tudo isso o torna um gênero de escrita colaborativa e com características muito peculiares de produção multimodal. No entanto, o que acreditamos merecer destaque em relação à webaula é sua função de servir de principal mediadora da interação verbal que ocorre em cursos a distância, uma vez que é por intermédio dela (seja de que forma ela se configure) que boa parte da mediação didática que ocorre no AVA se concretiza. Estruturamos um quadro síntese do processo de escrita (Figura 7). Nele 
descrevemos os sujeitos envolvidos e o papel que exercem na produção.

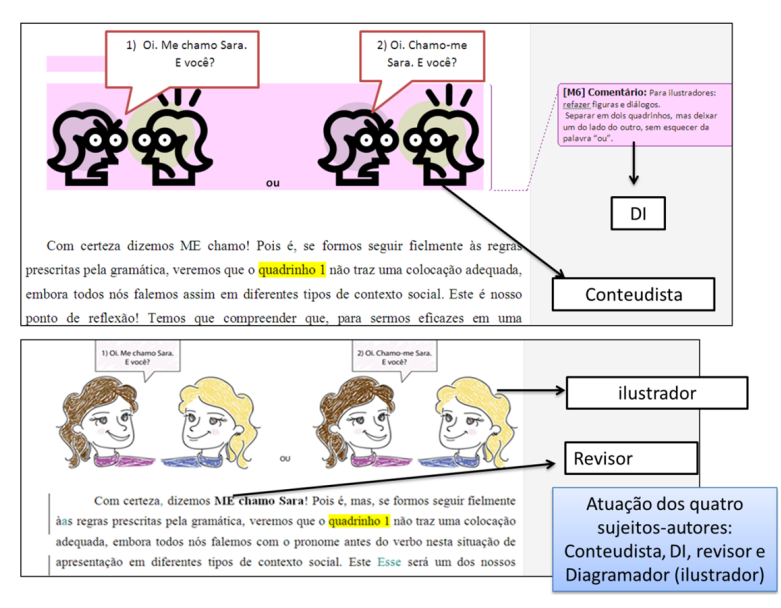

Figura 5: Intervenção escrita de todos os sujeitos-autores.

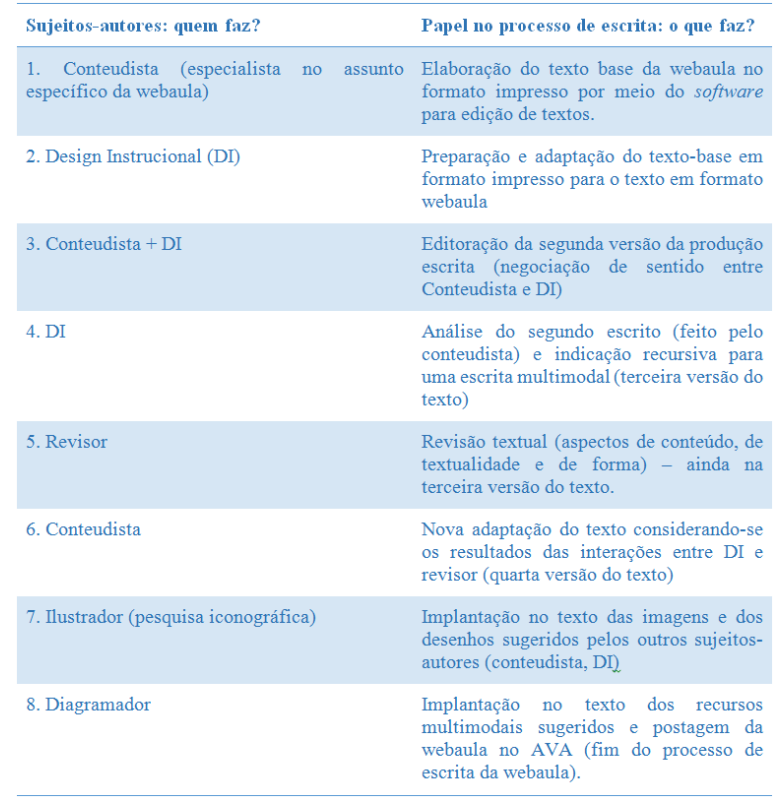

Figura 7: Síntese do processo de escrita.

É a partir dessa organização sistemática de escrita colaborativa que produzimos uma webaula no IFCE. As webaulas, obviamente, não são iguais, porque os sujeitos que as escrevem também não o são. Eles trazem concepções de escrita diferentes, perspectivas de linguagem distintas, conhecimentos conceituais e letramentos diferentes. Porém, para que o gênero tenha uma realização linguística e social efetiva, temos de ter uma base que norteie nossa produção, na qual nos apoiemos para realizar a tarefa de escrita colaborativa. Partimos de pressuposto, então, que o gênero webaula reúne características do gênero oral aula, de gêneros escritos de cunho didático (a própria escrita didática) e de gêneros que circulam no domínio hipertextual (aspectos multimodais e hipertextuais), tratando-se, portanto, de um gênero híbrido com características muito peculiares de produção colaborativa.

Também neste processo de escrita, os sujeitosautores devem levar em conta a correspondência entre os conteúdos, as informações, os links, os ícones, os áudios, as imagens, a interface, etc. Em resumo: todos os sujeitos devem ter letramento digital suficiente para escreverem o gênero webaula e não um texto que mais se assemelhe a outro gênero, como um artigo científico, por exemplo. E mais: como este gênero é do domínio hipertextual, os autores têm de estabelecer uma estrutura de escrita que também favoreça diferentes formas

Figura 6: Webaula de Português Instrumental no AVA com a interface de e-book interativo. 
PRODUÇÃO TEXTUAL DO GÊNERO WEBAULA NO FORMATO E-BOOK: DESCRIÇÃO DO PROCESSO DE ESCRITA

acessos à informação; que estimule a pesquisa em outras fontes, em outro gêneros que existem na hipermídia, a fim de apresentar diferentes pontos de vista sobre aquele tema que está sendo trabalhado na webaula. Por isso, os sujeitos-autores não podem esquecer que escrever para um Ambiente Virtual de Aprendizagem requer conhecimento da escrita multimodal na qual se apresentará o texto, pois os alunos adotarão diferentes estratégias de leitura diante de um gênero acadêmico hipertextual.

\section{Considerações Finais}

$\mathrm{O}$ e-book interativo trata-se de uma interface escolhida pela Diretoria de Educação a Distância do IFCE para disponibilizar no Ambiente Virtual de Aprendizagem as webaulas dos cursos de Licenciatura em Educação Profissional e Aperfeiçoamento em docência na educação profissional nos níveis básico e técnico. É este gênero de escrita colaborativa que fará a comunicação entre professores-alunos-material didático no curso. O processo de escrita desse gênero se desenvolve pela negociação de sentidos estabelecida pelos sujeitos-autores. Cada sujeito que intervém na escrita atribui novos sentidos ao texto.

A construção da webaula se inicia com o texto verbal feito pelo conteudista (primeira versão) e vai sendo multimodalizado por outros sujeitos-autores até chegar à sua versão final hipertextual. Esta forma de escritura nos leva a refletir sobre os limites da multimodalidade, sobre as possibilidades de uma escrita hipertextual multimodal, sobre autoria no Ambiente Virtual de Aprendizagem, sobre interação, sobre uma escrita dialógica e dialogal de cunho acadêmico, sobre as bases conceituais para uma escrita colaborativa na web, etc. Vimos que escrever um gênero hipertextual multimodal como a webaula é muito complexo e requer um tipo de letramento muito específico dos sujeitos-autores.

\section{REFERÊNCIAS}

ALMENARA, J. C. Las web para la formación. In: IBANEZ, J. S.; CABERO-ALMENARA, J.; GOMEZ, J. I. A. (Ed.). Tecnologías para la Educación: diseño, producción y evaluación de medias para la formación docente. 5. ed. Madrid: Alianza Editorial, 2011. 319 p.

ARAUJO, N. A.; HISSA, D. L. A.; ZAVAM, A. S. Material Didático em EaD: a produção de webaula (no prelo).

ARETIO, L. G. La educación a distancia: de la teoría a la práctica. 4. ed. Barcelona: Editorial Planeta S.A., 2011. 328 p.
ASIMSTEN, J. C. Producción de contenidos para Educación Virtual: guía de trabajo del docente-contenedista. 1. ed. Madrid: VirtualEduca, 2007. $179 \mathrm{p}$.

BATISTA, M. Ángel H. Consideraciones para el diseño didático de ambientes virtuales de aprendizaje: una propuesta basada en las funciones cognitivas del aprendizaje. Revista Iberoamericana de Educación, v. 5, n. 38, 2001. Disponível em: <http: //www.rieoei.org/deloslectores/1326Herrera.pdf $>$. Acesso em: 3 nov. 2013.

Las fuentes del aprendizaje en ambientes virtuales educativos. Revista Iberoamericana de Educación, 2001. Disponível em: <http: //www.rieoei.org/deloslectores/352Herrera.PDF $>$ Acesso em: 3 nov. 2013.

HERAS, A. R. de las. El tercer espacio. Revista de Tecnologias de la Información y Comunicación Educativas, n. 2, 2001.

HUEROS, A. D.; FRANCO, M. D. G. Diseño y producción de paginas web educativas. In: IBANEZ, J. S.; CABERO-ALMENARA, J.; GOMEZ, J.

I. A. (Ed.). Tecnologías para la Educación: diseño, producción y evaluación de medias para la formación docente. 5. ed. Madrid: Alianza Editorial, 2011. 319 p. 